\title{
Co-Disposal Plant and Distribution System to Allow the Proper Closure of Exxaro's Hillendale Mine Site
}

\author{
J.M. Rusconi Paterson \& Cooke Consulting Engineers (Pty) Ltd, South Africa \\ P. Goosen Paterson \& Cooke Consulting Engineers (Pty) Ltd, South Africa \\ J. Venter Exxaro, South Africa
}

\begin{abstract}
The run of mine ore from the Exxaro Hillendale Heavy Minerals operation contains distinct fine and coarse fractions. The fine fraction consists mainly of clay and is referred to as slimes. The coarse fraction consists mainly of sand. These are separated during the mineral recovery process. Traditionally these have been disposed of separately, either by refilling mining voids or in a tailings dam. However, in order to ensure that the land is returned to an arable state, the clay and sand need to be remixed in the same proportion in which they occur in the ore body and placed in a sufficiently thick capping layer as part of the final rehabilitation process on the mine site.
\end{abstract}

During 2007, Paterson \& Cooke were asked to design a plant capable of distributing 400 tonnes per hour of this mixture. It is required to finely control the ratio of sand to clay and deposit it at a high enough yield stress to prevent segregation on placement.

This paper is a case study of the design, construction and commissioning of the plant.

\section{$1 \quad$ Introduction}

The Exxaro Hillendale Heavy Minerals mining operation is situated near Richard's Bay on the east coast of South Africa. Mining is performed by hydraulically cutting into the face of the ore body which moves progressively forwards leaving large voids. The mined ore slurry collects in controlled pools from where it is pumped to the processing plant. The heavy mineral extraction process requires that the fine (mainly clay) and coarse sand fractions in the ore are separated resulting in two tailings streams. The coarse particle slurry is disposed of by de-watering it with in situ cyclones leaving a relatively stable sand mass. The clay fraction slurry, known as slimes cannot be de-watered in this way and needs to be contained in order for it to dry and eventually gain stability. The sand component is thus used both to refill mined out voids and also, through cycloning, to create containment walls behind which the slimes is deposited. Thus, much of the mining area, which is nearing the end of its life, consists of either coarse fraction sand or slimes contained in a dam.

As part of the closure process, Exxaro is required to return the land to an arable state, suitable for the growing of sugar cane. This requires the clay and sand to be re-mixed in the same proportion that they occur naturally. This needs to be distributed over the entire mine site in a sufficiently thick layer. If too much water is present in this mixture when deposited, the coarse and fine fractions tend to segregate, especially when deposited on slopes. To prevent this, the mixture needs to be pumped and deposited with as high a solids content as is practically possible.

Sections of this paper describe the plant that was designed and built to remix and distribute the mixture. It also discusses the hydraulic design process and some of the issues that arose during commissioning.

\section{System description}

\subsection{Process overview}

A simplified process flow diagram for the rehabilitation plant is shown in Figure 1. Coarse sand from sump SU10 is pumped from the Primary Wet Plant over a distance of about $1000 \mathrm{~m}$ to a bank of de-watering cyclones. The cyclone underflow is placed in a stockpile area where the sand drains and dries naturally to a 
moisture content of about $12 \%$. The overflow is returned to the Primary Wet Plant. The dry sand is loaded by front end loaders onto a conveyer which loads it into the mixing tank.

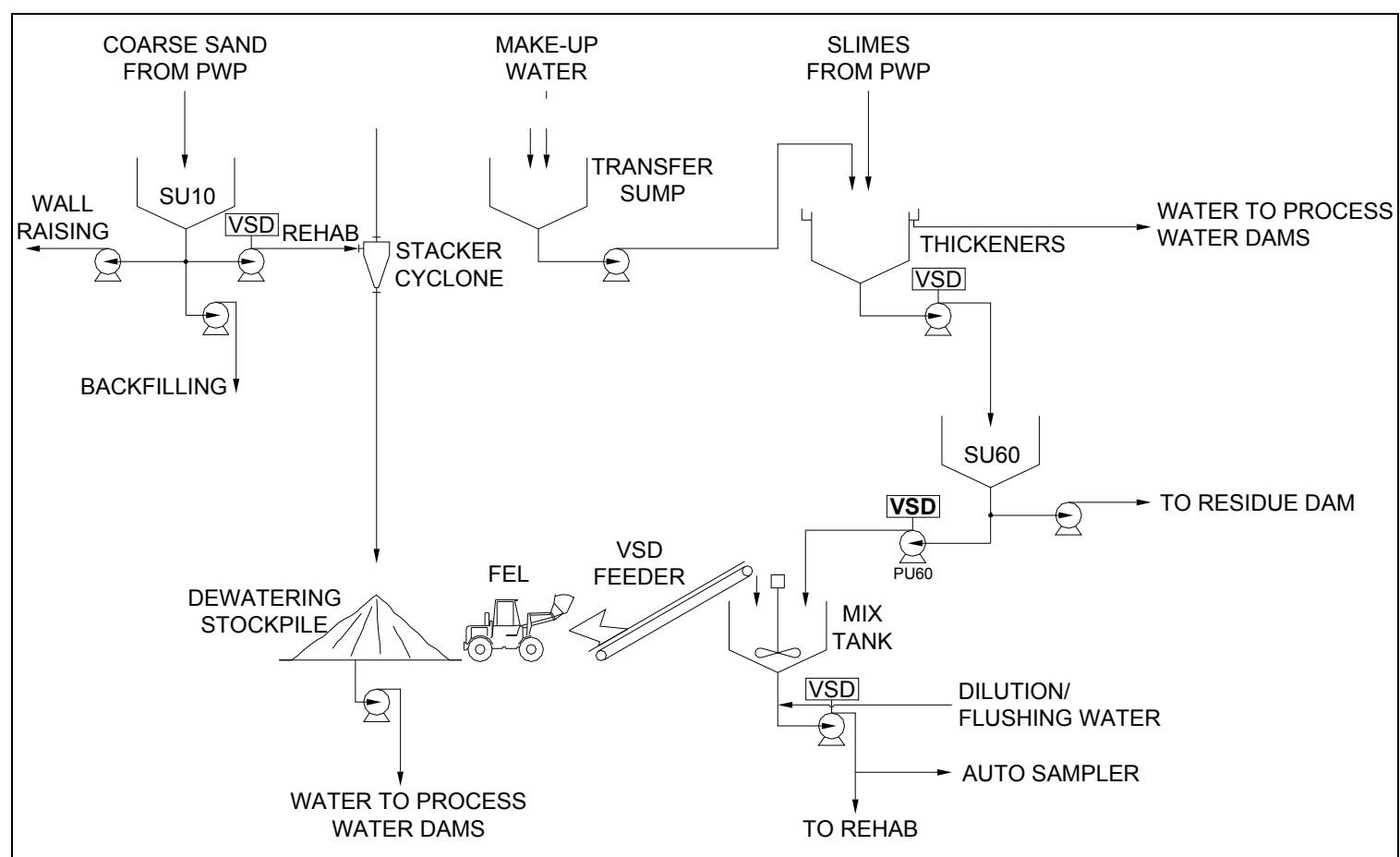

\section{Figure 1 Process flow diagram}

The slimes portion of the tailings is transferred from the paste thickener underflow collection tank, SU60, to the mixing tank by a variable speed driven pump. The pump speed is automatically adjusted to feed slimes to the mixing tank at a preset sand to slimes ratio (by dry solids mass). The mixture is pumped from the tank for distribution around the mine site, placed either from spigot discharges (on hilly areas) or from an open ended pipe to fill flat areas that have been divided up into paddocks. The major components are shown in Figure 2.

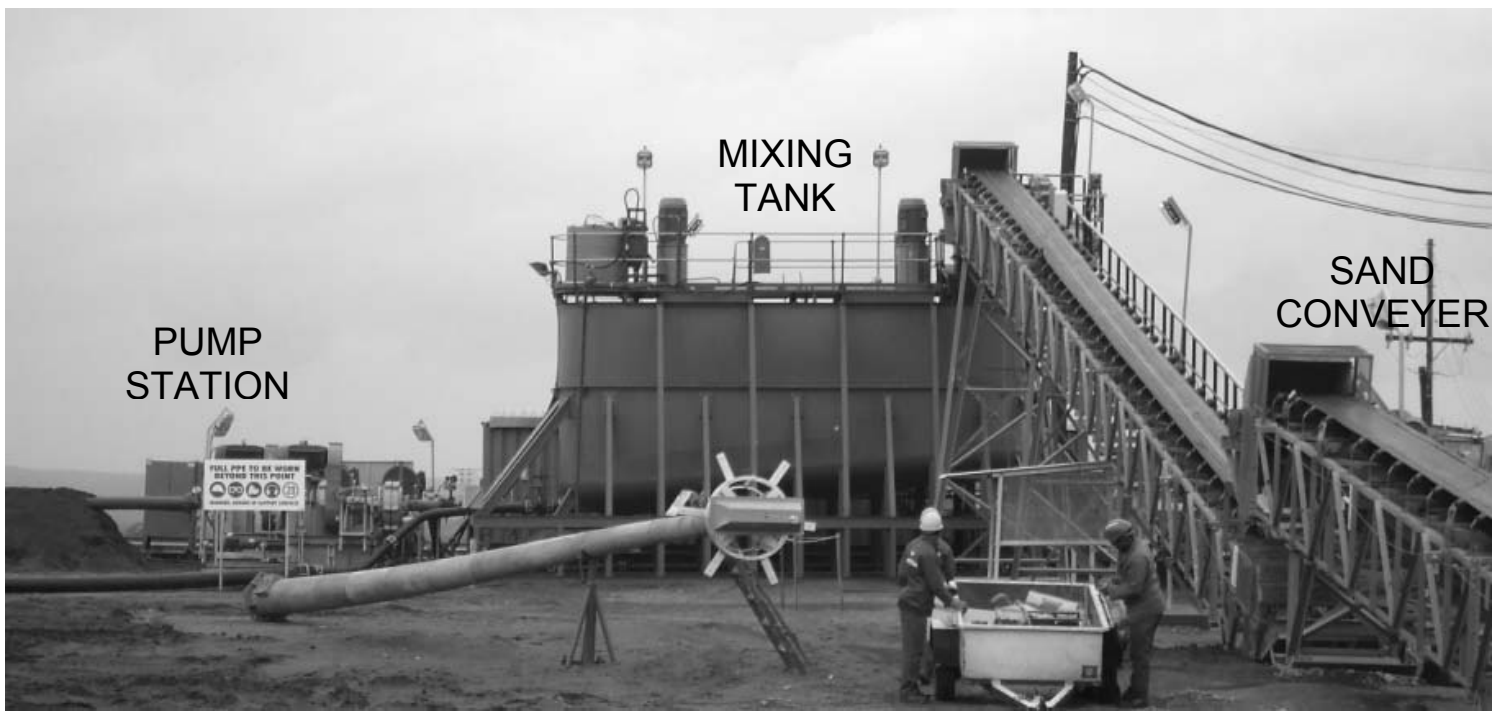

Figure 2 Major components 


\subsection{Control system}

The plant is controlled by a Distributed Control System (DCS) located at the main mine processing plant. The primary operator set points are as follows:

a) The sand dry solids feed rate which is selected between preset limits.

b) The ratio of sand to slimes, either 70:30 or 80:20.

The sand tailings belt feeder is slaved to an in-line load cell which automatically varies the belt speed to maintain a constant dry solids feed rate. The variable speed drive (VSD) of the slimes delivery pump is slaved to the sand delivery rate setting and selected mixture ratio such a constant solids ratio is delivered to the mixing tank.

The pump station for distributing the mixture is slaved to the mixing tank level. The first two pump stages always run, with the VSD making continuous adjustments to the flow rate. Stages 3 and 4 start up when additional flow is required. In order to prevent over-pressurisation of the pump and piping system, dilution water is automatically introduced at the suction side of the pump station if the pressure reaches a critical level.

\subsection{Pump station}

The pump station is skid mounted and is equipped with Warman pumps as shown in Table 1. A general view is given in Figure 3.

\section{Table 1 Slurry pumps}

\begin{tabular}{lllllll}
\hline Stage & Motor & $\begin{array}{l}\text { Motor } \\
\text { Control }\end{array}$ & $\begin{array}{l}\text { Lining } \\
\text { (Casing) }\end{array}$ & $\begin{array}{l}\text { Lining } \\
\text { (Impeller) }\end{array}$ & Size & Type \\
\hline 1 & $185 \mathrm{~kW}$ & VSD & Metal & Metal & $10 / 8$ & AH \\
$2 \& 3$ & $160 \mathrm{~kW}$ & FSD & Metal & Metal & $10 / 8$ & AH \\
4 & $160 \mathrm{~kW}$ & FSD & Metal & Metal & $10 / 8$ & AHP \\
\hline
\end{tabular}

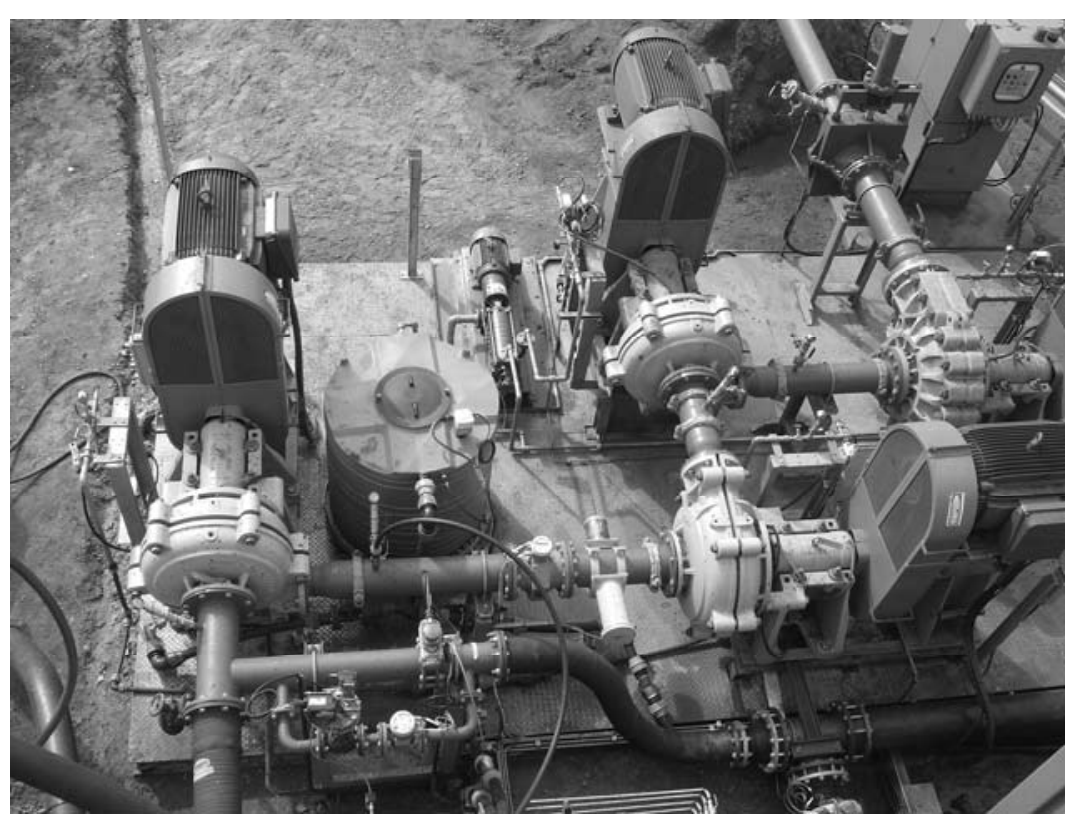

Figure 3 General view of pump station 
High pressure gland service water for stages 3 and 4 is provided by a KSB multistage pump (32/10) with $15 \mathrm{~kW}$ motor. Stages 1 and 2 are equipped with mechanical seals, flushed with low pressure, gravity fed water.

\subsection{Deposition - slopes}

The spigot deposition systems were designed to equally distribute the material between 20 off $75 \mathrm{~mm}$ diameter HDPE pipes positioned along the top of the shaped sand dune (placed sand tailings). Clamps on rubber pipes fitted over the HDPE pipe ends are used to control the flow through each spigot to balance the flow across the pipes.

Initially the rubber pipes could not be clamped tightly enough onto the HDPE pipes and were forced off at the distribution points. Beads were created on the ends of the HDPE pipes to enable the rubber pipe to be fitted securely. This simple solution successfully addressed this problem.

When all 20 pipes were fed from a single point the material could not be distributed equally across the 20 pipes at the far ends of the placement area where the pressure has reduced substantially. Additional valves were added onto the spigot systems to select either the left or right hand side of the spigot system. This increased the pressure in the spigot pipeline sufficiently to be able to distribute the material equally across the selected 10 pipes.

The $75 \mathrm{~mm}$ diameter HDPE pipes filled with material are difficult to move to assist the spreading of the material across the full width of the dune. Trials are being undertaken with HDPE, lay flat and kanaflex to find an optimal solution that can be moved across the dunes with greater ease.

\subsection{Deposition - paddocks}

Initially, the paddock deposition system consisted of two $200 \mathrm{~mm}$ diameter pipelines that were gradually retracted from the paddocks during deposition.

Later, the operational team elected to deposit the material from a single point into the paddock. The optimal solution is still to be selected.

\section{$3 \quad$ Pumping system hydraulics}

The slimes (paste thickener underflow) behaviour was relatively well understood based on ongoing test work and operational experience with the thickened slimes pumping system at Hillendale mine. There had, however been no previous experience with pumping this slimes/sand blend prior to this project. A test program was thus initiated to gain an understanding of the slurry behaviour to provide input to the design process.

\subsection{Slurry flow behaviour and associated test work}

The slimes fraction is composed, to a large extent, of clay minerals and other predominantly sub 45 micron particles, with typically $30 \%+45$ micron (sand) content. Historical data from the slimes thickening and pumping system indicated a slimes slurry thickener underflow density of typically $1.23 \mathrm{t} / \mathrm{m}^{3}$, with less than $5 \%$ frequency of occurrence of slimes density less than $1.19 \mathrm{t} / \mathrm{m}$ or greater than $1.27 \mathrm{t} / \mathrm{m}^{3}$. The thickened slimes yield stress value can vary significantly (typically between 20 and $60 \mathrm{~Pa}$ ) as indicated by the sample of data presented in Figure 4. It should be noted that the composition of the slimes slurry in terms of clay/sand content is variable around the nominal $30 \%$ sand value. In order to correlate the slimes yield stress with the slimes slurry concentration, the yield stress data in Figure 4 are correlated against volume concentration of the fine ( -45 micron) fraction in the slimes.

The primary unknown in tackling the hydraulic design of the pumping system was the flow behaviour of the sand/slimes blend, and specifically how the yield stress of the mixture would be related to the mix ratio and the yield stress of the slimes feed stream. This issue was tackled by constructing a pilot scale mixing plant on the mine site which allowed for various sand/slimes blends to be produced and the slurry flow behaviour to be investigated through the measurement of pipeline pressure gradient as a function of flow rate. In addition, this pilot facility provided the opportunity to gain valuable experience which could be applied in the design 
of the production unit and provided the opportunity to conduct placement trials with the sand/slimes mixtures.

The sand/slimes mixture was found to behave as a Bingham plastic fluid. A summary of results obtained from the pilot plant in terms of yield stress as a function of the mixture density for two distinct blends is presented in Figures 5 and 6 . The yield stress range 60 to $100 \mathrm{~Pa}$ is highlighted on the graphs as this is the range that had been identified from placement trials as being the target mixture consistency. This yield stress range was found to provide the required non-segregating behaviour while still providing a sufficiently fluid mixture to achieve the desired distribution on placement.

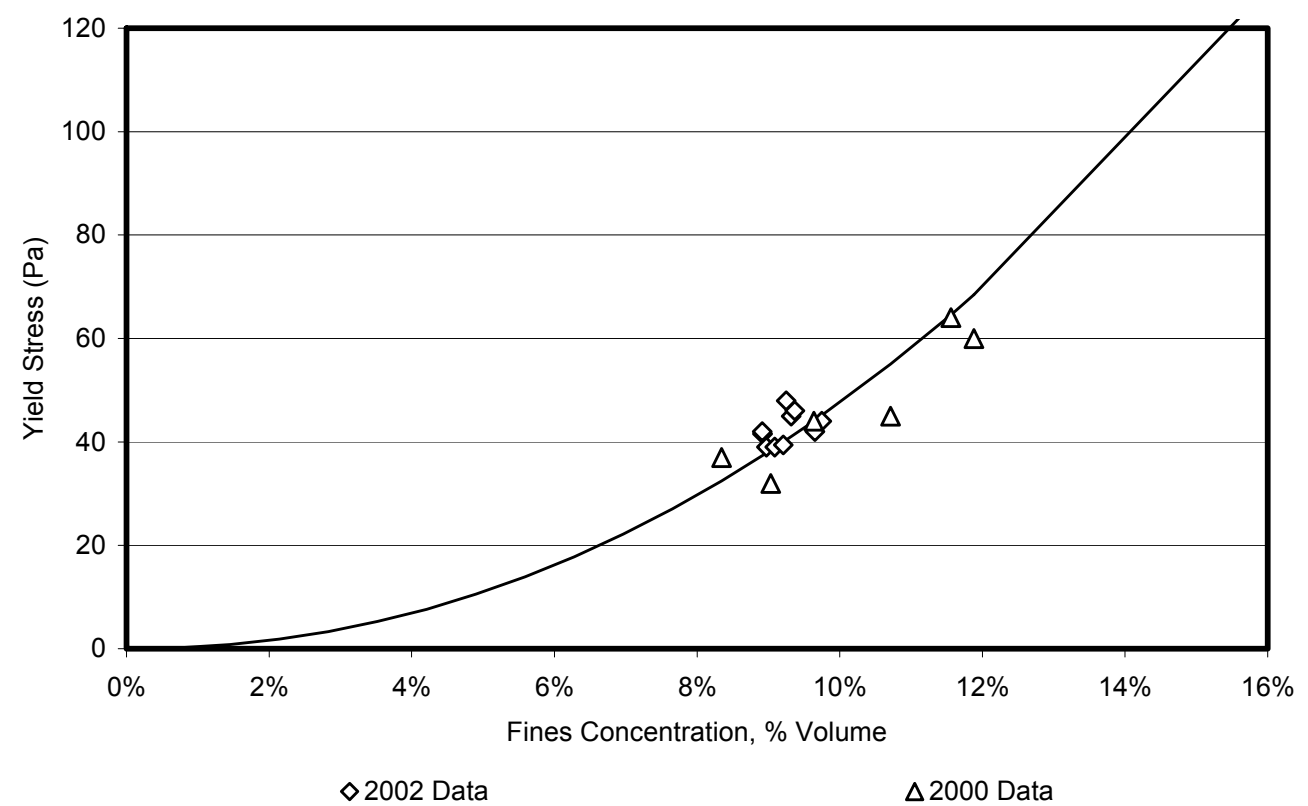

Figure 4 Thickened slimes yield stress as a function of volume concentration of fines $(-45 \mu \mathrm{m}$ fraction)

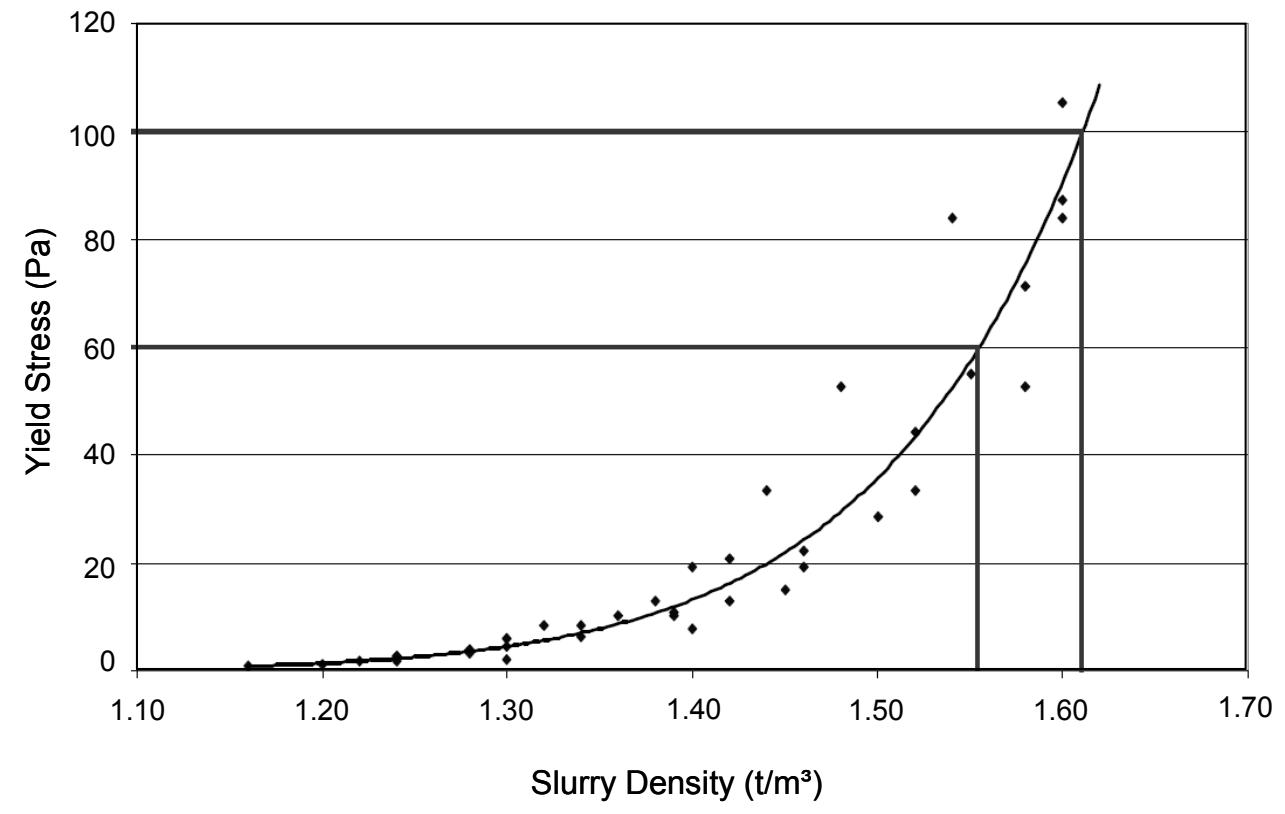

Figure 5 Rehabilitation slurry mix yield stress versus slurry density (70:30 sand/slimes mix) 


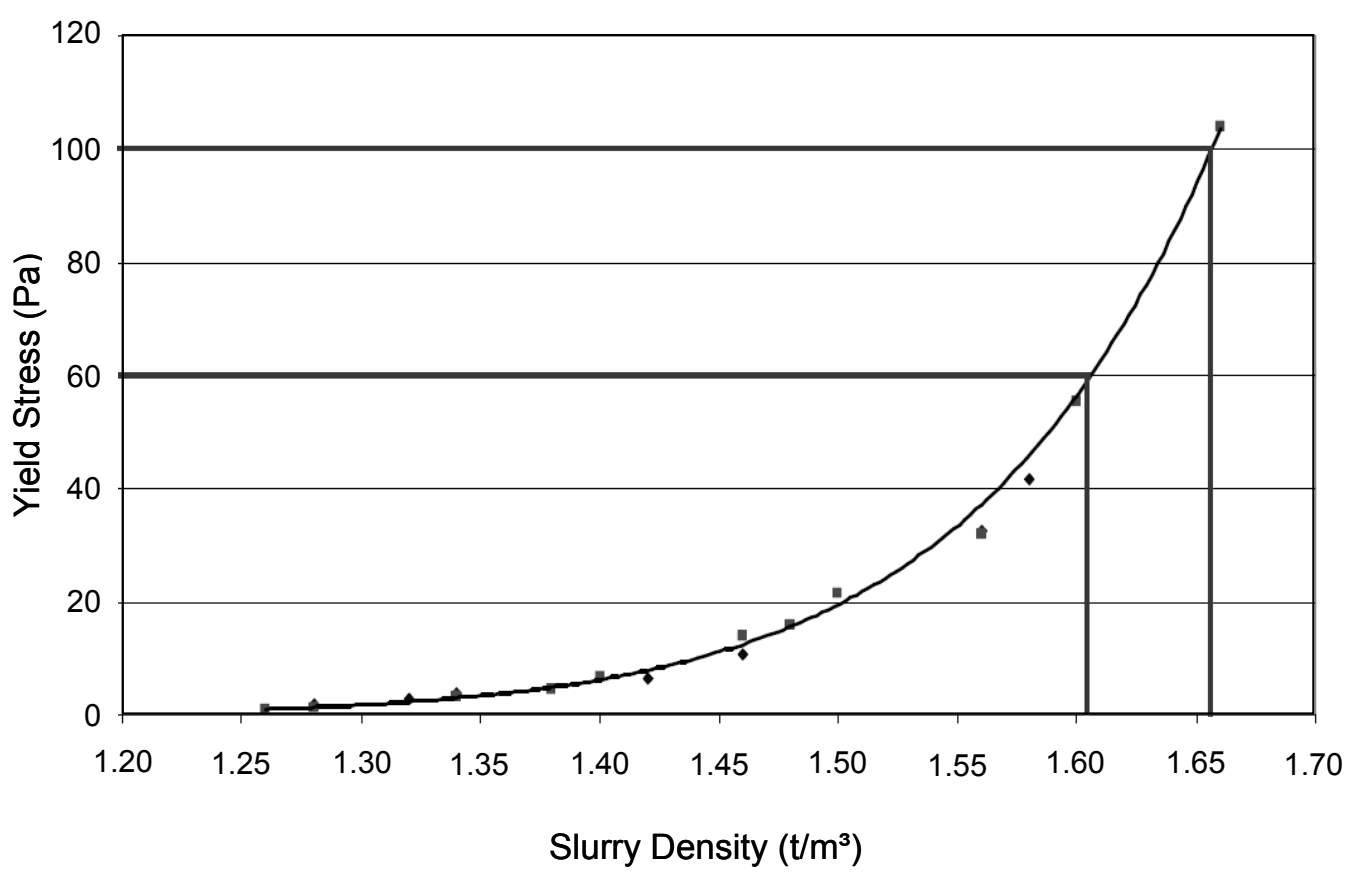

Figure 6 Rehabilitation slurry mix yield stress versus slurry density (80:20 sand/slimes mix)

\subsection{Hydraulic design}

For this relatively high yield stress slurry, the pipeline flow regime is laminar over the full range of operating conditions in the pipeline. The pumping pressure is thus primarily a function of yield stress, pipe diameter and pumping distance. Because of the Bingham plastic behaviour, the pumping pressure is relatively insensitive to flow rate for a given pipe size. Within the design range, the Bingham plastic viscosity was found to be relatively constant and a value of $0.04 \mathrm{~Pa}$.s was applied in the calculations.

A $250 \mathrm{~mm}$ NB pipeline size was selected for the system as this was found to provide an appropriate compromise between pipe cost and pumping infrastructure cost. The piping consists of a combination of flanged steel pipe (in the more permanent and higher pressure areas close to the pump station) and HDPE pipe in the lower pressure sections near the discharge end which will be moved more frequently as required by the rehabilitation program. The calculated pipeline system curve for a range of yield stress values and typical discharge location (approximately $1500 \mathrm{~m}$ pumping distance and $-30 \mathrm{~m}$ elevation change) is shown in Figure 7. This illustrates the potentially wide operating range in terms of pump head, assuming that the yield stress could potentially vary within the range shown.

Positive displacement (PD) pumps appear to be appropriate in this application since the PD pump performance characteristic would simplify the system control, considering the highly variable pumping pressure requirements. However, a decision was made to employ centrifugal slurry pumps on this system rather that positive displacement pumps in order to minimise the capital cost. It was accepted that this will add significantly to the system operation and control. This is also in line with the requirement to limit system pressures as far as possible to facilitate the use of HDPE pipe as far as possible. 


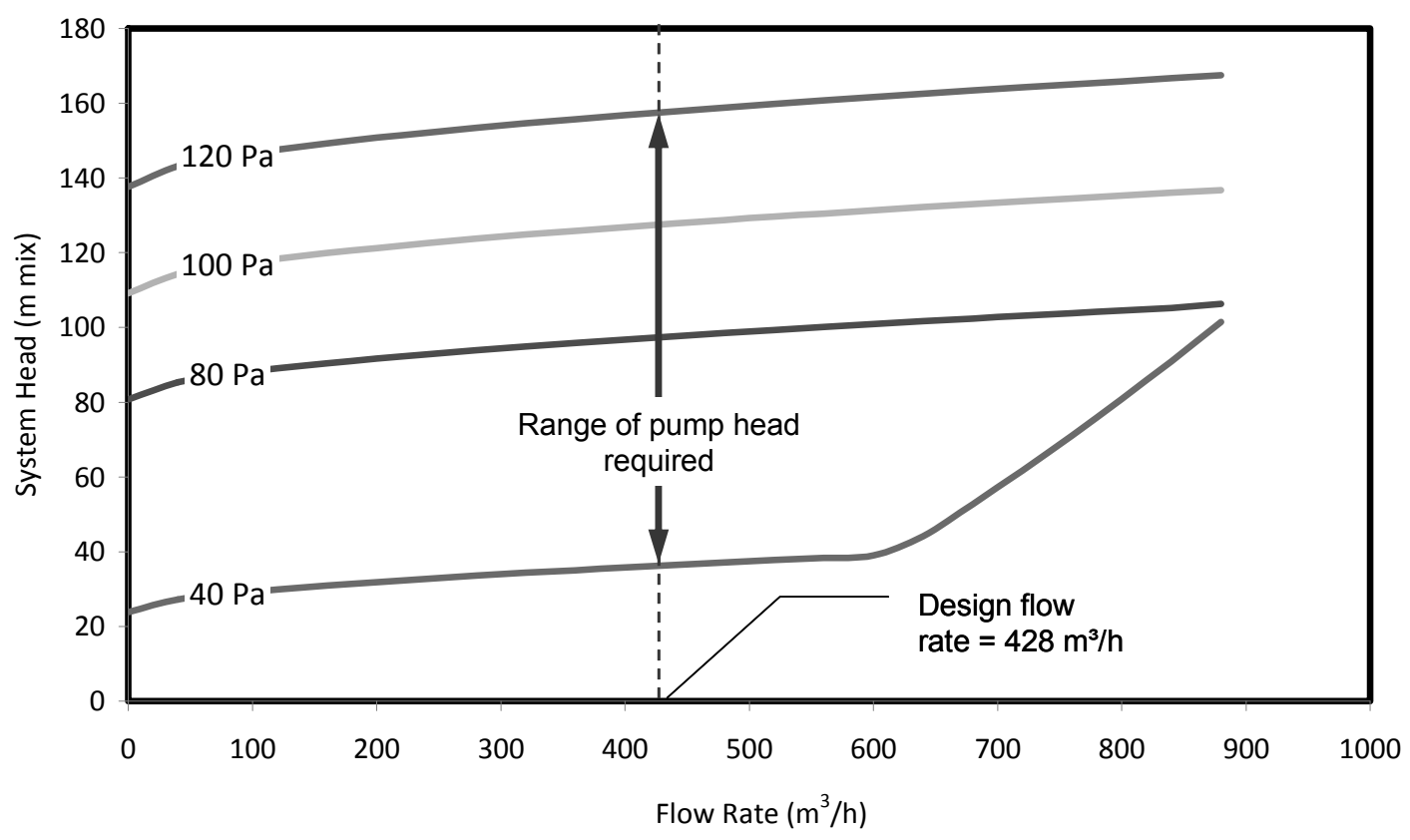

Figure 7 Pipeline system curve (typical)

\section{Operational experience}

This section discusses some of the issues that arose during commissioning.

\subsection{Fines feed}

Control of the slimes feed rate to the mixing plant has proved problematic. The rate fluctuates due to significant variations in the slimes yield stress between 20 and $40 \mathrm{~Pa}$. At high yield stress values the feed pump is sometimes unable to supply the slimes demand although this is generally when the plant is called upon to run at higher than the original design level of $400 \mathrm{tph}$. Thus, at high throughputs, the operator has to monitor the slimes and sand feeds and adjust the plant capacity slightly according to the available slimes flow rate.

An investigation is underway to upgrade the slimes pumping system by adding another pump in series to increase its ability to supply sufficient slimes to the mixing plant under all yield stress conditions.

\subsection{Sand loading}

Two front end loaders are now in use. It was initially planned to use only one of larger capacity but soft surface conditions made it difficult to load sand at a high enough, continuous, rate.

\subsection{Sand conveyer}

The specification for the design and manufacture of the conveyors called for a system that could be pivoted around a fixed point to enable the conveyor system to be moved from side to side to reduce the tramming distance of the front end loaders between the sand stockpile and the sand feed hopper.

The design that was accepted consisted of a $40 \mathrm{~m}$ fixed conveyor and two $20 \mathrm{~m}$ conveyors with a vibratory sand hopper.

The specification stated that the movable conveyors had to be designed in such a way that they could be lifted by a 20 tonne excavator. The suppliers initially supplied a four legged sling to lift the movable conveyors, however this proved unsafe. An asymmetric lifting beam was subsequently manufactured and supplied that enables the excavator to lift and move the $20 \mathrm{~m}$ conveyors. 
The $40 \mathrm{~m}$ conveyer did initially give alignment problems due to poor quality belting as well as the alignment of the conveyor structure. The number of reinforcing plies in the belt was not consistent throughout the belt which caused it to drift from side to side. The manufacturer installed splicing plates on the conveyor structure to straighten it and replaced the belt. These changes have solved the initial problems.

The variable speed drives controlling the speed of the sand feed hopper, mixers and first stage pump create high frequency noise in the electrical control cables that resulted in unexplained motor errors which in turn would trip the motor of the first conveyor. Various measures have been taken to reduce the effect of the high frequency noise. These include additional earthing, reconfiguration of the MCC Panels and separation of the VSD cables from other electrical cables.

\subsection{Mixing}

Initially, sand and slimes were added simultaneously into the empty mixer during start-up. However it was found that the mixer was incapable of suspending the sand, resulting in large quantities being left at the bottom. Adding a too high concentration of sand had the same effect. If sand was left to accumulate at the bottom of the tank it caused the pump station suction pipe to block. The problem was eliminated by ensuring that the tank is filled to the operating level with slimes before any sand is added. The slime tends to hold the sand in suspension when it is added which allows sufficient time for mixing. The mixed material can be left at the operating level for up to two days without significant quantities of sand settling out. When the plant is started up after standing time, the mixers are simply left to run for 10 minutes before additional material is added.

Initially, the required operating level of the mixing tank was fairly high. This resulted in a very narrow tank level operating band. Changes were made to the mixers, making them effective at greater range of levels. This has made operating the system much easier and more stable.

With these changes, the plant is now delivering slimes/sand mixture to the mine site at the 400 tph design rate and correct mixture ratio. Improvement of the slimes delivery pumping system will allow even higher rates to be delivered.

\section{Conclusions}

Based on previous experience with the Hillendale sand and slimes as well as pilot plant test work, the codisposal plant was designed, built and commissioned. As expected, the commissioning process did highlight some technical and operational challenges. However, with technical improvements and more disciplined operating procedures, the plant is now delivering design tonnages at the required mixture ratios. Changes to the slimes pumping system will allow an even greater throughput. The proactive use of co-disposal from the start of future mining operations may allow this technology to be used to reduce life of mine (LOM) operating costs rather than merely as a mine closure process.

\section{Acknowledgements}

The authors would like to thank Exxaro who kindly gave permission for this paper to be published.

\section{References}

Exxaro KZN Sands (2007) Hillendale dune rehabilitation system concept philosophy, Richard's Bay, South Africa Krause, B. (2004) Development and application of paste fill using dry tailings, Proceedings of the Fifth International Seminar on Paste and Thickened Tailings, A.B. Fourie, P. Slatter and A. Paterson (eds), Australian Centre for Geomechanics, Perth, Australia, Paper 16. 